\title{
Allozyme variation of oleaster populations (wild olive tree) (Olea europaea L.) in the Mediterranean Basin
}

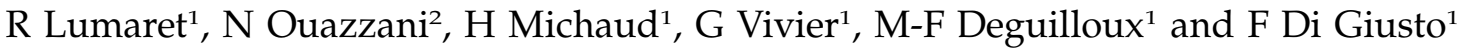 \\ ${ }^{1}$ Centre d'Ecologie Fonctionnelle et Evolutive CEFE/CNRS (U.P.R. 9056), 1919 Route de Mende, F-34293 Montpellier Cedex 05, France; \\ ${ }^{2}$ Ecole Nationale d'Agriculture, Département d'Arboriculture, B.P. S40, Meknès, Morocco
}

\begin{abstract}
As a result of the early domestication and extensive cultivation of the olive tree throughout the Mediterranean Basin, the wild-looking forms of olive (oleasters) presently observed constitute a complex, potentially ranging from wild to feral forms. Allozyme variation was analysed at 10 loci in 31 large and 44 small oleaster populations distributed in various habitats of the Mediterranean Basin and in two populations of the wild subspecies Olea europaea subsp (ssp) guanchica, endemic to the Canary islands and closely related to oleasters. At eight polymorphic loci, 25 alleles were identified. Genetic evidence that nondomesticated oleasters still survive locally was provided by the occurrence of four and one alleles shared exclusively by the eight western and two eastern oleaster populations, respectively, which were
\end{abstract}

collected in forests potentially containing genuinely wild forms according to environmental, historical and demographic criteria. As reported previously from cytoplasmic and RAPDs analysis, substantial genetic differentiation was observed between the eastern oleaster populations genetically close to most olive clones cultivated in the Mediterranean Basin, and the western populations that are related to the wild Canarian populations. In addition, the occurrence of significantly lower heterozygosity in cultivated olive than in oleasters, whatever their origin, suggests that intensive selection involving inbreeding has taken place under cultivation to obtain particular characteristics in the olive cultivars. Heredity (2004) 92, 343-351, advance online publication, 25 February 2004; doi:10.1038/sj.hdy.6800430

Keywords: allozyme variation; Olea europaea L. ssp Sylvestris; oleaster populations; olive domestication

\section{Introduction}

The olive tree (Olea europaea L.) is one of the most ancient domestic, cultivated plants characteristic of the Mediterranean Basin (Zohary and Spiegel-Roy, 1975). The crop (O. europaea subsp (ssp) europaea ( = O. europaea var. sativa Lehr.)) has been of immense importance as the principal source of edible oil for the peoples of the Mediterranean region for many millennia. Palynological and anthracological (fossil charcoal) evidence supports the occurrence of wild olive forms (O. europaea sssp sylvestris (Miller) Hegi (= var. oleaster (Hoffmanns and Link) DC), in forests of the Mediterranean Basin during the Paleolithic (Liphschitz et al, 1991). According to anthracological studies, during the Neolithic (100007000 years ago), use of wild olive (oleasters) persisted in several parts of the Basin (Liphschitz et al, 1991; Zohary and Hopf, 1993). Clear signs of olive domestication (olive oil presses) come from the Near East during the Early Bronze Age (second half of the fifth millennium BP) (Zohary and Spiegel-Roy, 1975; Liphschitz et al, 1991). It is currently assumed that individual oleaster trees showing superior performance for size and/or oil content of fruit were selected empirically and propagated vegetatively as clones, using cuttings that were

Correspondence: $R$ Lumaret, Centre d'Ecologie Fonctionnelle et Evolutive, CEFE 1919, Route de Mende, F-34293 Montpellier Cedex 05, France.

Email:lumaret@cefe.cnrs-mop.fr

Received 18 February 2003; accepted 12 December 2003 planted directly or, more recently, grafted onto indigenous oleasters. From these propagated individuals, olive cultivars were developed and distributed by various successive human migrations throughout the Mediterranean Basin, especially from East to West although the selection of olive cultivars was multilocal and included originally western plant material, as shown by genetic studies based on allozyme polymorphism (Lumaret et al, 1997), on RAPD profiles and on mitochondrial RFLPS (Besnard and Bervillé, 2000; Claros et al, 2000; Besnard et al, 2001a, b; Bronzini de Caraffa et al, 2002a) as well as inter-simple sequence repeat (ISSR) markers (Vargas and Kadereit, 2001). Deforestation probably reduced native oleaster populations and the geographic dissemination of cultivars favoured multiple contact areas and hybridisation between cultivated olive and indigenous oleasters that are fully interfertile. This may have led to the progressive disappearance of the original genetic characteristics of the wild oleasters (Zohary and Spiegel-Roy, 1975).

Throughout the Mediterranean Basin, oleaster olives differ from the cultivated clones by the presence of spinescent juvenile shoots, smaller fruits characterised by less fleshy mesocarp and lower oil content, as well as by a long juvenile stage that may last for several decades in some individuals. As reported previously (Zohary and Spiegel-Roy, 1975), whatever their parental origin (wild or cultivated) any olive progeny grown from seed usually shows the morphological characters specific to oleasters. These therefore constitute a complex of 
wild-looking olives potentially ranging from wild to feral forms (ie secondary sexual derivatives of the cultivated clones or products of hybridisation between cultivated trees and nearby oleasters) (Zohary and Spiegel-Roy 1975; Zohary and Hopf, 1993).

During the last five decades, controversy has developed as to whether the oleasters observed at present have originated exclusively by naturalisation from cultivated plants (Chevalier, 1948) or whether genuinely wild native forms still survive in some forests of the Mediterranean Basin. In this latter case, only the oleasters observed in secondary habitats (the edges of cultivated or abandoned orchards) would be feral (Zohary and Spiegel-Roy, 1975; Zohary and Hopf, 1993). In Australia, oleasters derived from olive cultivars introduced 200 years ago, and which are bird-dispersed plants, have proved to be successful invaders in numerous biotopes, including forests (Spennemann and Allen, 2000). Moreover, knowledge about the dissemination distance of olive pollen by wind (Griggs et al, 1975), from recent studies of seed dispersal of wild olive by birds in Spain (eg Alcantara et al, 2000), and from local reports about the extensive use of olive stones from olive groves for forestation in several Mediterranean countries suggest that genuinely wild olive populations may be restricted to very few isolated forest areas.

In several previous studies, the nuclear genetic variation of oleasters was analysed over the Mediterranean Basin using RAPD markers (Besnard et al, 2001a, b) and, in more restricted areas, using RAPDs (Bronzini de Caraffa et al, 2002a, b), AFLPs (Angiolillo et al, 1999) and allozyme polymorphism (Lumaret et al, 1997; Lumaret and Ouazzani, 2001). When wide areas were sampled, a clear nuclear genetic differentiation was observed between oleasters from the eastern and western parts of the Mediterranean Basin. In the present work, we analysed in detail the genetic variation of numerous oleaster populations distributed over the Mediterranean Basin. These populations were found to grow in various habitat conditions, such as the edge of olive groves, abandoned groves and noncultivated areas including forests. Moreover, several Mediterranean forests considered as good candidates for containing genuinely wild oleasters were selected according to several climatic, historical and demographic criteria. Allozymes at several independent loci analysed previously in numerous cultivated olive trees (Ouazzani et al, 1993; Ouzzani et al, 1995; Lumaret et al, 1997) were considered as appropriate codominant markers to characterise oleaster genetic variation. The objectives of the study were: (1) to analyse genetic variation in oleaster populations according to their geographical location and environmental conditions and (2), if possible, to identify allozymes specific to the oleaster populations selected as good candidates for containing genuinely wild material. Such specific allozymes were expected to be coded by low-frequency alleles and/or to be expressed by genes linked to loci coding for deleterious characters or for traits not suitable for olive domestication based exclusively on fruit characters. In both cases, allozymes would be expected to be absent in cultivated olives and in the feral oleaster forms derived totally or partially from them. A third objective was to compare allelic diversity and heterozygosity between oleasters and cultivated olive, two closely connected partners of the same species, which reproduce sexually and vegetatively, respectively.

\section{Materials and methods}

\section{Tree sampling}

At least 20 trees (38.25 individuals on average) were sampled in 31 large oleaster populations distributed over the Mediterranean Basin (Figure 1 and Table 1). Two additional large populations (nos. 32 and 33) of the wild subspecies, O. europaea ssp guanchica P. Vargas, J. Hess, Muños Garm and Kadereit (O. cerasiformis (Webb and Berth) Kundel and Sunding), endemic to the Canary Islands, were sampled in two sites on Grand Canary Island (Figure 1). There is no evidence that this subspecies has been involved with olive domestication (Zohary, 1994), but it was found to be very closely related to Mediterranean oleasters (O. europaea ssp sylvestris) on the basis of chloroplast DNA variation and RAPD and ISSR markers (Hess et al, 2000; Lumaret et al, 2000; Médail et al, 2001).

Of the large populations, 10 were sampled in forest areas considered to be good candidates to contain genuinely wild oleasters according to three criteria: (i) past and present climatic conditions suitable for wild olive growth (humid and subhumid variants of the thermo-Mediterranean climate with an average minimum temperature of the coldest month and annual rainfall exceeding $5^{\circ} \mathrm{C}$ and $450 \mathrm{~mm}$, respectively (Daget, 1977; Rivas-Martinez, 1981; Terral and Arnold-Simard, 1996); (ii) past and present isolation (usually more than $10 \mathrm{~km}$ ) from areas of cultivated olive trees; and (iii) large oleaster populations (several thousands of trees) to reduce the influence of occasional pollen and seed flow from cultivated olive areas. In the eastern part of the Mediterranean Basin, where olive trees have been extensively cultivated for long periods, we used less restrictive criteria to identify candidate areas, more particularly for population size and isolation distance from cultivated olive areas. Candidate areas were not found in Egypt, Syria, Turkey, Crete or Greece, even though oleaster populations do occur in forested areas in those countries. Out of the 10 selected forests, two were located in the south of Spain (populations 22 and 23), two in central Morocco (populations 27 and 28), one in southern France (population 18), one in south Corsica (population 14), one in Sicily (population 10), one in Tunisia (population 30), one in central Cyprus (population 3) and one in Upper Galilee, Israel (population 1). Most populations were in evergreen oak forests located in uneven areas, and several were previously royal hunting grounds that have become natural reserves. Among the 21 other large sampled populations, 16 were located in habitats undisturbed by cultivation, including forests and degraded formations, and five (populations $7,21,25,26$ and 31) were in abandoned groves containing multicentenary oleaster trees that had been used to graft various olive cultivars.

In addition, 44 small populations were sampled. Their locations are indicated in Figure 1. Most of these populations consisted of a restricted number of oleasters that were sampled exhaustively (from six to 19 trees, 13.2 individuals on average). For two Israeli populations, a restricted number of trees was scored for the whole set of 


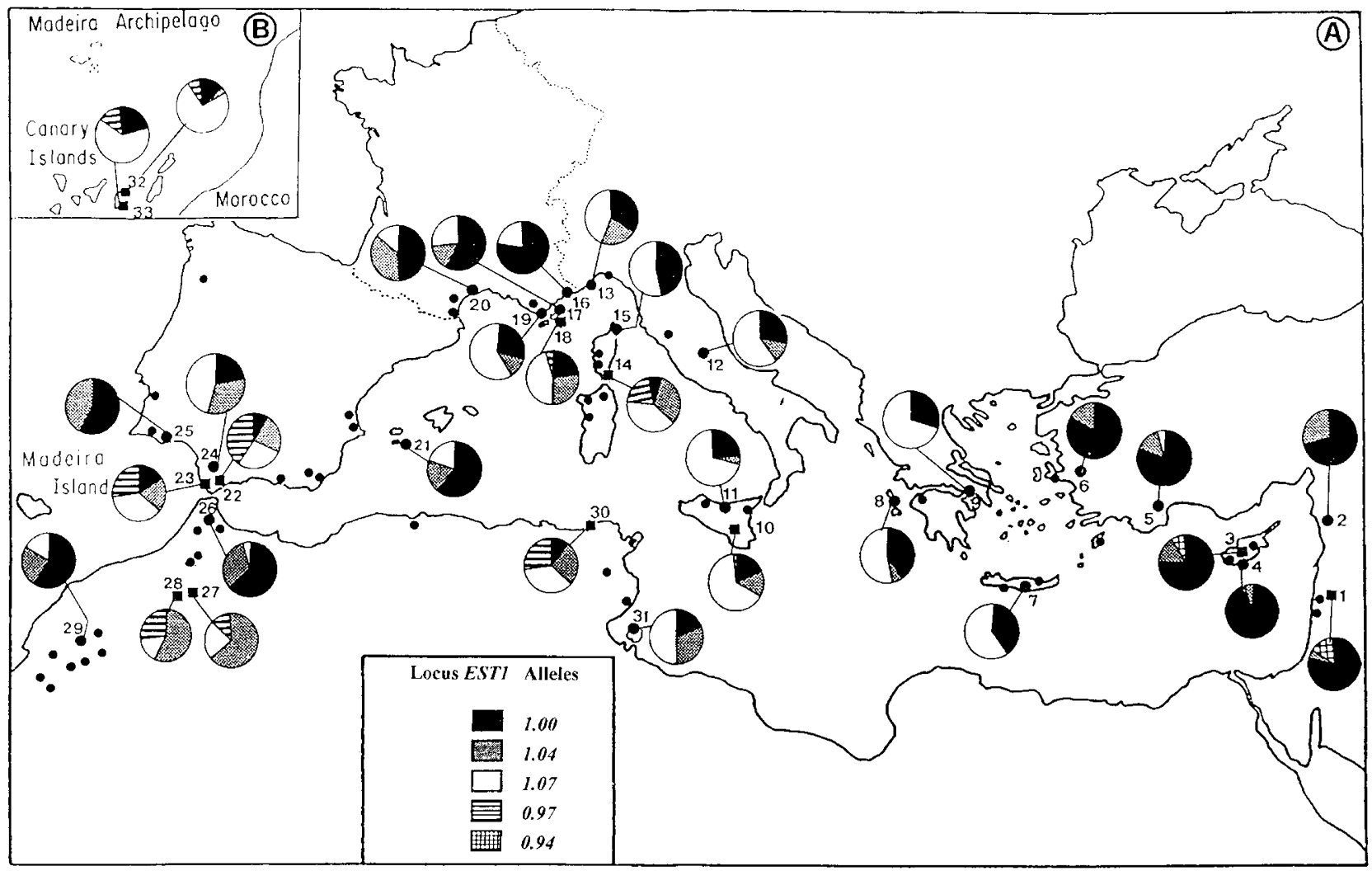

Figure 1 Geographical distribution of five alleles observed at the Est-1 locus in the 31 large oleaster populations sampled over the Mediterranean Basin and in the two Canarian populations of $O$. guanchica. The location of 44 additional small populations is indicated by small black dots.

loci. Among the 44 small populations, 10 were located in forests, eight were groups of old trees used for grafting and 26 were small groups of oleasters growing at the edges of olive groves or within abandoned groves, that is, in environmental conditions where secondary feral forms of oleasters are expected to grow.

The results from analysis of oleasters populations were compared with data obtained previously at the same allozyme loci in the domesticated olive, including widely used cultivars, most of them from the olive germplasm world collection of Cordoba (Spain), and additional clones cultivated locally but not described as formal cultivars (Lumaret and Ouazzani, 2001). In all, 525 cultivated clones were analysed for the whole set of allozyme loci and most of the results were published previously (Ouazzani et al, 1993, 1994; Ouzzani et al, 1995; Trujillo et al, 1995).

\section{Allozyme analysis}

Proteins were extracted from leaves and used to perform horizontal starch-gel electrophoresis for six enzyme systems: phosphoglucose isomerases (EC 5.3.1.9. with two polymorphic duplicated loci, Pgi-1-2), alcohol dehydrogenases (EC 1.1.1.1., locus Adh-1), phosphoglucomutases (EC 2.7.5.1., with two loci, Pgm-1 and Pgm-2), leucine amino peptidases (EC 3.4.11.1., locus, Lap-1), esterases (EC 3.1.1.2., with two loci, Est-1 and Est-2) and malate dehydrogenases (EC 1.1.1.37., with two loci, $M d h$ 1 and $M d h-2)$. The protein extraction method, the composition of gels and electrode buffers, the techniques used to stain allozyme bands and the genetic determin- ism of the systems analysed from controlled crosses were described previously (Ouazzani et al, 1993).

\section{Data treatment}

At each locus, genotypic and allelic frequencies were assessed from a survey of gel phenograms. Data from olive material cultivated in the eastern and the western part of the Mediterranean Basin and those from the 44 small populations were pooled, respectively. Allozyme data were used to calculate the percentage of monomorphic populations $(\mathrm{M})$, the total number of alleles per locus (At), the mean (A), and the minimum and maximum number of alleles per locus and per population. The numbers of alleles and genetic diversity values were compared between populations or between groups of populations by Mann-Whitney $U$-tests. Allele genotypes were also used to calculate observed heterozygozity (Ho). Percentage comparisons were carried out for $\mathrm{M}$ and Ho values. Total genetic diversity $(\mathrm{Ht})$, withinpopulation genetic diversity (Hs) and the proportion of diversity resulting from gene differentiation among populations (Gst) and among groups of populations, were estimated by using GENETIX (4.2) software package (Belkhir et al, 2001).

Genotypic data were analysed using F-statistics (Wright, 1965). Departure of Fis values from zero was tested for each population at each locus ( $\mathrm{Li}$ and Horvitz, 1953). All analyses mentioned above were performed using the GENEPOP (3.1) software package (Raymond and Rousset, 1995). 
Table 1 Country, sample size, wild (W) and ferral (F) status hypothesised according to environmental, historical and demographic criteria, percentage of polymorphic loci (PL), mean number of alleles per locus (Al), genetic diversity within population (Hs) and Fis values in 31 large populations of oleasters and two populations of guanchica (nos. 32 and 33) analysed at eight allozyme loci

\begin{tabular}{|c|c|c|c|c|c|c|c|}
\hline Pop. & Country/island & Sample size & Status & $P L(\%)$ & $A l$ & $\mathrm{Hs}$ & Fis \\
\hline 1 & Israel & 38 & W & 100 & 2.29 & 0.346 & +0.004 \\
\hline 2 & Syria & 33 & $\mathrm{~F}$ & 100 & 2.14 & 0.366 & +0.009 \\
\hline 3 & Cyprus & 20 & W & 086 & 2.29 & 0.379 & -0.006 \\
\hline 4 & Cyprus & 26 & $\mathrm{~F}$ & 100 & 2.14 & 0.248 & -0.010 \\
\hline 5 & Turkey & 40 & F & 100 & 2.29 & 0.337 & -0.005 \\
\hline 6 & Turkey & 40 & $\mathrm{~F}$ & 086 & 2.00 & 0.319 & +0.004 \\
\hline 7 & Crete & 32 & F & 100 & 2.14 & 0.420 & +0.017 \\
\hline 8 & Greece & 36 & F & 100 & 2.29 & 0.444 & +0.005 \\
\hline 9 & Greece & 34 & $\mathrm{~F}$ & 100 & 2.14 & 0.414 & +0.087 \\
\hline 10 & Sicily & 42 & W & 100 & 2.86 & 0.483 & +0.172 \\
\hline 11 & Sicily & 52 & $\mathrm{~F}$ & 100 & 2.57 & 0.468 & -0.014 \\
\hline 12 & Italy & 34 & F & 100 & 2.29 & 0.442 & +0.072 \\
\hline 13 & Italy & 32 & $\mathrm{~F}$ & 100 & 2.29 & 0.461 & -0.084 \\
\hline 14 & Corsica & 39 & W & 100 & 2.86 & 0.480 & +0.040 \\
\hline 15 & Corsica & 44 & $\mathrm{~F}$ & 100 & 2.43 & 0.423 & +0.140 \\
\hline 16 & France & 69 & $\mathrm{~F}$ & 100 & 2.14 & 0.413 & +0.122 \\
\hline 17 & France & 37 & $\mathrm{~F}$ & 100 & 2.43 & 0.450 & +0.006 \\
\hline 18 & Port-Cros & 40 & W & 100 & 2.57 & 0.429 & +0.007 \\
\hline 19 & France & 29 & $\mathrm{~F}$ & 100 & 2.43 & 0.421 & -0.046 \\
\hline 20 & France & 38 & $\mathrm{~F}$ & 100 & 2.29 & 0.432 & +0.016 \\
\hline 21 & Ibiza & 32 & $\mathrm{~F}$ & 100 & 2.29 & 0.418 & +0.190 \\
\hline 22 & Spain & 45 & W & 100 & 3.14 & 0.499 & +0.084 \\
\hline 23 & Spain & 44 & W & 100 & 3.14 & 0.522 & +0.140 \\
\hline 24 & Spain & 40 & $\mathrm{~F}$ & 100 & 2.43 & 0.459 & +0.074 \\
\hline 25 & Spain & 40 & $\mathrm{~F}$ & 100 & 2.14 & 0.429 & +0.042 \\
\hline 26 & Morocco & 32 & $\mathrm{~F}$ & 100 & 2.43 & 0.488 & -0.063 \\
\hline 27 & Morocco & 48 & W & 100 & 2.86 & 0.468 & +0.144 \\
\hline 28 & Morocco & 35 & W & 100 & 2.71 & 0.454 & +0.180 \\
\hline 29 & Morocco & 24 & $\mathrm{~F}$ & 100 & 2.43 & 0.496 & +0.001 \\
\hline 30 & Tunisia & 38 & W & 100 & 2.86 & 0.450 & +0.096 \\
\hline 31 & Tunisia & 52 & $\mathrm{~F}$ & 100 & 2.57 & 0.523 & +0.112 \\
\hline 32 & Canary & 26 & W & 100 & 2.86 & 0.392 & -0.042 \\
\hline 33 & Canary & 37 & W & 100 & 2.71 & 0.381 & -0.021 \\
\hline
\end{tabular}

Nei's (1978) genetic distances and, to maximise the effects of rare alleles, the $\chi^{2}$ distances, weighted by allele frequencies averaged over all populations, were calculated between pairs of populations. The respective positions of the populations, estimated by the distances between them, were plotted in a multidimensional space and then projected onto a plane by nonmetric multidimensional scaling (or proximity analysis) (Escoufier, 1975). The same distances were also used as the basis for a hierarchical cluster analysis (UPGMA), with 'average distance' used as the clustering criterion. Clusters at specific levels of agglomeration (total range 0-100\%) were mapped onto the diagram obtained from the multidimensional scaling, so that results from the two methods could be compared. These analyses were performed using the Biomeco computer package (Anon, 1989). Moreover, for each pair of populations, the relationship between genetic structure and geographical isolation was assessed by comparing geographical and genetic distances. Using GENETIX software (Belkhir et al, 2001), the correlation was then quantified (Z-value) using a Mantel test that compares the matrices of geographical and genetic distances. The measured $Z$ was compared with that obtained with 1000 permutons by randomising one of the two matrices. Relationships between geographical distance and genetic structure were considered as significant when the true $Z$-value was higher than $99 \%$ of the $Z$-values obtained with 1000 permutons $(P<1 \%)$.

\section{Results}

\section{Allelic variation in oleaster populations}

Among the 10 allozyme loci analysed, two (Pgm-1 and $M d h-1)$ were monomorphic for the same allele in all populations studied. At the eight other loci, 25 distinct alleles were identified in oleasters, Pgi-1-21.60, Pgi-1$2^{1.00}$ Pgi-1-2 ${ }^{0.60}, P g m-2^{1.14}, P g m-2^{1.00}, P g m-2^{0.90}$, Adh-1 ${ }^{1.12}$, Adh-1 1.00, Adh-1 ${ }^{0.92}$, Est-1 1.07, Est-1 1.04, Est-1 1.00, Est-1 ${ }^{0.97}$, Est-1 ${ }^{0.94}$, Est-2 ${ }^{1.03}$, Est-2 ${ }^{1.00}, E s t-2^{0.94}, E s t-2^{\text {null }}, M d h-2^{0.79}$, Mdh-2 $2^{1.00}$, Lap-1 $1^{1.02}$, Lap-1 $1^{1.00}$, Lap-1 $1^{0.97}$, Lap $-1^{0.94}$ and Lap-1 ${ }^{0.92}$. Of these alleles, 19 were also identified in the small oleaster populations and in the cultivars that have been shown to possess four additional rare alleles distributed very locally (Ouazzani et al, 1993, 1995). Allele distribution at the highly polymorphic Est-1 locus in the 31 large oleaster populations and the two populations of O. europaea ssp guanchica is shown in Figure 1. At that locus, a clear genetic differentiation is observed between the populations from the eastern part of the Mediterranean Basin (Israel, Syria, Cyprus and Turkey), characterised by the predominance of allele Est $-1^{1.00}$ and the other populations (including those from the Canary island) where several other alleles (particularly Est-1 ${ }^{1.07}$ ) were present at high frequency. In addition, two alleles (Est-1 ${ }^{0.97}$ and Est-1 ${ }^{0.94}$ ) were observed exclusively in the oleasters of the 10 areas considered as good candidates for containing genuinely 
wild olive. Est-1 ${ }^{0.97}$ (ranging from 4 to $32 \%$ ) was found in each of the eight candidate oleaster populations located in the western part of the Mediterranean Basin and in the two Canarian populations. In the eastern part of the Basin, Est-1 $1^{0.94}$ was observed exclusively in the population 3 located in Cyprus (8\%) and in a population from Upper Galilee (14\%). At the other loci, three additional alleles were found to be specific to the selected areas, namely, Lap-10.94 (from 7\% to 22\%) observed in the populations 22 and 23 from Andalusia and in the two Canarian populations, Lap- $1^{1.02}$ identified in six populations (22 and 23 from Andalusia, 27 and 28 from Morocco and 32 and 33 from Canary islands) at a frequency ranging from 20 to $39 \%$ and $P g m-2^{0.90}$ (4-15\%) found in the eight candidate areas located in the western part of the Mediterranean Basin.

The average genetic distance value among the 31 large populations scored at the eight polymorphic loci was 0.143 (range $0.011-0.321$ ) for Nei's distance and 0.043 (range 0.012-0.087) for $\chi^{2}$ distance. In Figure 2, the eight populations selected in the western part of the Mediterranean Basin as good candidates to contain genuinely wild oleasters and the two populations from Canary islands that share several specific allozymes (see above) are located on the left side of the plan, parted by axis 2, whereas the two populations selected in the eastern part of the Basin, the unselected populations (whatever their geographical origin) and the two groups of cultivars are located on the right side of the plan. Three sets of populations could be distinguished at the $75 \%$ level of agglomeration (a critical value in the agglomeration process) in the UPGMA analysis. A first set (on the left in Figure 2) consists of the four populations selected in the most western part of the Basin (South of Spain and Morocco) and the two Canarian populations. These six populations share several alleles (eg Lap-1 ${ }^{0.94}$ and Lap-1.02) that were observed exclusively in the far western part of the Mediterranean Basin. The second set clustered together most of the oleaster populations and consisted of three subsets identified at the $40 \%$ level of agglomeration. One subset clustered together four populations of selected areas in the more central part of Mediterranean Basin (South of France, Corsica, Sicily and Tunisia). In these populations, most of the alleles specific to the selected areas were observed at very low frequencies. The two other subsets consisted exclusively of unselected populations, one of two Moroccan populations (26 and 29) and the other of 15 populations from a range of geographical areas and environmental conditions in the western and central parts of the Mediterranean Basin. When the 15 populations were parted into 11 and four populations from undisturbed and disturbed areas, respectively, no significant difference could be observed between the allelic distributions of the two groups of populations. A third set gathered together the most eastern oleaster populations (1-6) and the groups of olive clones cultivated in the eastern and western parts of the Basin, respectively. As compared to the populations from the western and central part of the Mediterranean Basin, the eastern oleaster and cultivated material and most cultivated olive clones from western areas are characterised by higher Pgm-2 ${ }^{1.00}, A d h-1^{1.12}, E s t-1^{1.00}$ and $L a p-1^{0.97}$ frequency, lower $A d h-1^{0.92}$ frequency and the absence of Est-1 $1^{1.07}$ and Lap-1 ${ }^{0.92}$. However, in a few local western cultivars (mainly from Sicily, Corsica and Andalusia), allelic distributions were close to those observed in the oleaster populations that were growing in the same areas. Within the third set, at $40 \%$ agglomeration level, two subsets were identified which parted the two populations selected for containing wild oleasters and characterised by a specific allozyme (see above) from the other populations.

For the 10 large populations selected to contain genuinely wild olive and for the eight populations of them growing in the western part of the Mediterranean Basin and considered separately, a positive relation

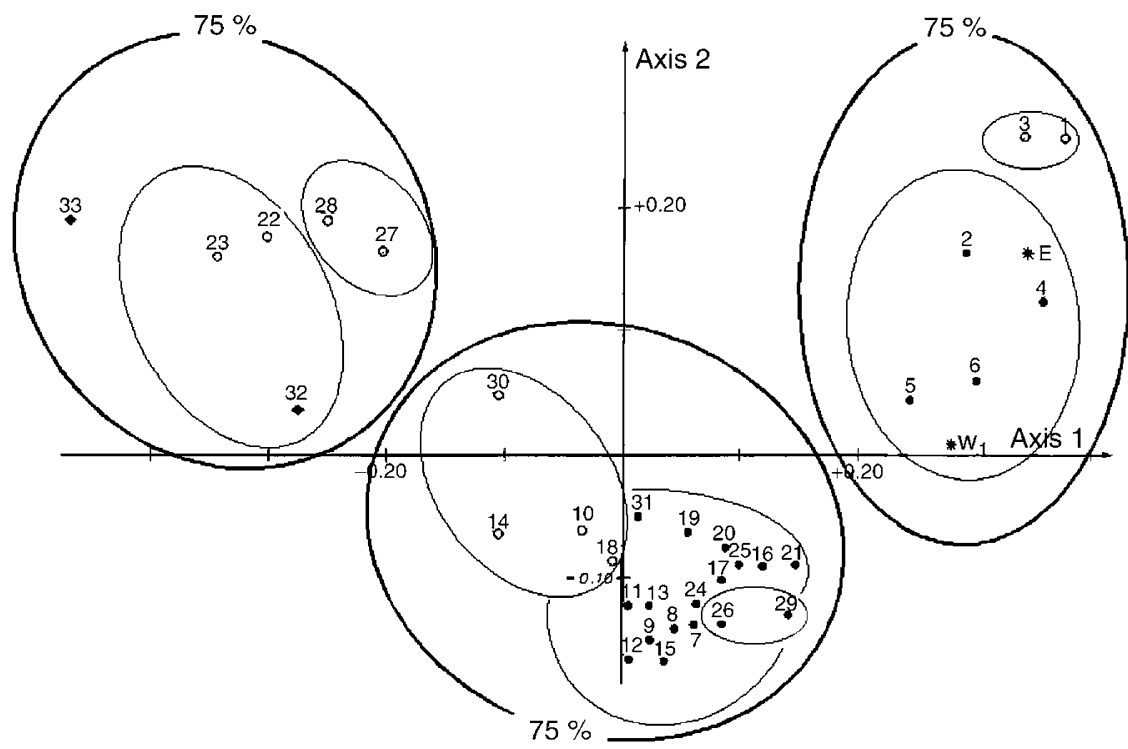

Figure 2 Position of 10 large oleaster populations selected as containing potentially genuinely wild olive $(\bigcirc)$, of 21 large unselected populations $(\bullet)$, of two Canarian populations of guanchica $(\bullet)$ and of two groups of cultivated olive () according to polymorphism at eight polymorphic allozyme loci. Multidimentional scaling from $\chi^{2}$ distances. Populations are clustered at the 40 and $75 \%$ levels of hierarchical clustering. 
Table 2 Percentage of polymorphic populations (P), total number of alleles per locus (At), mean (A) (minimum-maximum) number of alleles per population, total genetic diversity $(\mathrm{Ht})$, genetic diversity within populations ( $\mathrm{Hs})$, proportion of diversity between populations (Gst), observed heterozygosity (Ho) and Fis values at eight polymorphic allozyme loci in 31 large populations of oleasters

\begin{tabular}{|c|c|c|c|c|c|c|c|c|}
\hline Locus & P-value (\%) & At & A & $H t$ & Hs & Gst & Ho & Fis \\
\hline Pgi-1-2 & 100.0 & 3 & $2.61(2-3)$ & 0.466 & 0.457 & 0.02 & - & - \\
\hline Pgm-2 & 100.0 & 3 & $2.22(2-3)$ & 0.499 & 0.459 & 0.08 & 0.372 & -0.010 \\
\hline Adh-2 & 100.0 & 3 & $2.35(2-3)$ & 0.517 & 0.461 & 0.11 & 0.530 & -0.030 \\
\hline Est-1 & 100.0 & 5 & $3.10(2-4)$ & 0.681 & 0.546 & 0.20 & 0.499 & +0.123 \\
\hline Est-2 & 92.8 & 4 & $2.06(1-3)$ & 0.455 & 0.386 & 0.15 & 0.310 & +0.191 \\
\hline$M d h-2$ & 100.0 & 2 & $2.00(2-2)$ & 0.258 & 0.238 & 0.08 & 0.198 & -0.070 \\
\hline Lap-1 & 100.0 & 5 & $2.90(2-5)$ & 0.559 & 0.485 & 0.13 & 0.522 & +0.173 \\
\hline Mean 1 & 99.0 & 3.50 & 2.48 & 0.491 & 0.433 & 0.12 & 0.405 & +0.063 \\
\hline Mean 2 & 97.5 & 3.37 & 2.77 & 0.506 & 0.449 & 0.11 & 0.428 & +0.084 \\
\hline Mean 3 & 99.0 & 2.87 & 2.34 & 0.448 & 0.421 & 0.06 & 0.382 & +0.032 \\
\hline Mean 4 & 86.2 & 2.62 & 2.33 & 0.356 & 0.339 & 0.05 & 0.346 & -0.002 \\
\hline Mean 5 & 100.0 & 3.25 & 2.52 & 0.503 & 0.455 & 0.09 & 0.414 & +0.077 \\
\hline Mean 6 & 100.0 & 2.75 & 2.75 & 0.421 & 0.385 & 0.08 & 0.430 & -0.030 \\
\hline SP & 95.4 & 2.75 & - & 0.402 & - & - & 0.392 & - \\
\hline EC & - & 2.87 & - & 0.291 & - & - & 0.280 & - \\
\hline WC & - & 2.87 & - & 0.323 & - & - & 0.324 & - \\
\hline
\end{tabular}

Mean values calculated over the eight loci analysed in the 31 large populations (Mean 1), over the 10 oleaster populations selected for containing genuinely wild olive and the 21 unselected populations (Means 2 and 3, respectively), over the six and the 25 populations of eastern and western Mediterranean Basin (Means 4 and 5, respectively), over the two populations of O. europaea. ssp guanchica (Mean 6), over the 44 small oleaster populations (SP) and over the olive clones cultivated in the eastern and western parts of the Basin (EC and WC, respectively).

between genetic and geographical distances was obtained $(P<1 \%)$ from the results of the Mantel test $(Z=11482$ and 3787, Pearson's coefficient $r=0.861$ and 0.672 , respectively). For the 21 large unselected populations, a significant positive relation $(P<1 \%)$ was observed between genetic and geographical distances, but the correlation value was lower $(Z=27252$, $r=0.596$ ).

Table 2 shows the percentage of polymorphic populations, the mean and the range of alleles per population, several genetic diversity parameters, the observed heterozygosity and Fis values calculated at each of eight polymorphic loci analysed in the 31 large oleaster populations. Averages over these loci in these 31 populations (Mean 1), in the 10 populations from the selected forests (Mean 2), in the 21 unselected large populations (Mean 3 ), in the 25 populations located in the western and central parts of the Mediterranean Basin and in the six eastern populations (Means 4 and 5, respectively), and in the two populations from the Canary islands (Mean 6) are also indicated in Table 2. Maximum and minimum polymorphism and genetic diversity were observed at Est-1 and $M d h-2$, respectively. Of the average total diversity $(0.491$, range from 0.258 at Mdh-2 to 0.681 at Est-1), $12 \%$ was attributable to differentiation among populations (range from $2 \%$ at Pgi-1-2 to $20 \%$ at Est-1) (Table 2). Moreover, mean number of alleles per locus and per population and mean genetic diversity values were significantly higher $(P<0.05$ and $<0.01$, respectively) in the 10 populations selected to contain wild oleasters than in the 21 unselected populations. The Gst value between the two groups of populations was $5 \%$. For the same parameters, values were higher in the 25 large populations of the western and central distribution areas as compared to the six eastern populations $(P<0.01)$ and $10 \%$ genetic differentiation was observed on average between the two groups. Moreover, low polymorphism and low genetic diversity values were observed in the 44 small populations and, more particularly, in the two groups of cultivated olive (Table 2 ).

In the 31 large populations, Fis values averaged over loci and/or populations were not significantly different from zero except at Est-2 $(P<0.05)$ (Table 2). However, significant deviations from Hardy-Weinberg expectation were observed at some loci in several populations. Out of the 186 indices tested, 55 (four at $A D H-1,17$ at EST-1, 22 at EST-2 and 12 at $L A P-1$ ) positive deviations of Fis from 0 and 18 negative deviations (seven at $A d h-1$, nine at Mdh-2 and two at Pgm-2) were observed at either the 5 or the $1 \%$ significance level. Fst values were $14 \%$ between the 31 large populations and $6 \%$ between the eight putative wild populations of the western distribution area. In the 31 large populations, mean observed heterozygosity was high $(0.405$, range from 0.198 at Mdh-2 to 0.530 at $A d h$-2) (Table 2). A high heterozygosity value was also obtained in the two populations of $O$. europaea ssp guanchica from the Canary islands, whereas heterozygote frequencies were observed to be particularly low in the two groups of cultivated olive. Mean heterozygosity was significantly higher $(P<0.01)$ in the 10 populations from the selected forests than in the 21 other large populations.

\section{Discussion}

Genetic specificity of the populations identified to contain potentially genuinely wild form of oleasters

In the present study, substantial genetic variation was observed in oleasters. Average allele number per locus and heterozygosity values were particularly high. The highest genetic diversity values are observed in the 10 oleaster populations selected as the most likely to contain genuinely wild olive. In these populations, as compared to alleles occurring in both cultivated olive and 
unselected oleaster material, five additional alleles (four and one in the western and eastern parts of the Mediterranean Basin, respectively) were identified, which do not come therefore from cultivated olive material. As these alleles are distributed over large areas in several isolated forests, they have a low probability of being of recent origin. Instead, these alleles probably constitute evidence of the survival of indigenous wild oleaster populations, especially in the western part of the Mediterranean Basin, as suggested by Zohary and Spiegel-Roy (1975). In addition, three of these alleles are shared by the Canarian populations of O. europaea ssp guanchica and by the most occidental oleaster populations (more particularly those from the selected forests of Andalusia and Morocco), suggesting that the populations growing in the most westerly part of the species distribution have a common origin. Except for four very rare alleles, oleaster populations possess all the alleles already identified in cultivars. This result is consistent with our interpretation that the domesticated olive represents a subsampling of the genetic variation in genuinely wild olive, which persists today in the Mediterranean Basin.

A very significant association between vigour (related to the duration of oleaster juvenile phase), and genotype, at the two specific loci Est-1 and Lap-1, was observed previously in the progeny of a controlled cross between two cultivars and/or in oleaster populations grown for afforestation and in which individuals were the same age (Ouazzani et al, 1993). In subsequent analysis, this association re-emerged systematically and exclusively at the same loci in various oleaster material, which suggests that genetic linkage cannot be ruled out. It should be noticed that four of the five alleles characteristic of genuinely wild olive were found at the two loci associated with tree vigour, suggesting that this genetic association may have prevented the establishment of several alleles at these loci within cultivated material.

\section{Geographic allozyme variation in oleasters}

In the present study, substantial genetic differentiation was observed between the oriental and occidental oleaster populations with lower total and average genetic diversity in the former group of populations. This result is consistent with previous reports based on the analysis of chloroplast DNA variation (Amane et al, 1999; Besnard et al, 2002), on the combination of mitochondial DNA and RAPDs variation (Besnard and Bervillé, 2000; Besnard et al, 2001a), and on RAPDs and rRNA genes polymorphism (Besnard et al, 2001b). More particularly, very clear genetic differentiation based on the occurrence of distinct allozymes was observed between genuinely wild oleaster populations from the western and eastern parts of the Mediterranean Basin, respectively, suggesting that they may have distinct phylogeographical origins. In the present work, evidence is provided that the most western populations of the Mediterranean Basin are genetically close to the Canarian populations of ssp guanchica, which supports previous results obtained from plant material collected in the same areas and analysed using RAPD and ISSR markers (Hess et al, 2000). A very high correlation was found between geographical and genetic distances, showing a gradual western-eastern variation within the occidental group of populations (growing in the western and central parts of the Mediterranean Basin) and higher change in the eastern group of populations. However, the precise geographical boundary between the two population groups cannot be identified precisely because no candidate forest for containing genuinely wild olive was located in intermediate areas of the Mediterranean Basin and, more particularly, in Greece.

Within unselected oleaster populations, genetic differentiation based on both allele occurrence and frequency variation was also observed between the eastern populations (from Israel, Syria and Turkey) and the other populations (including those from Greece). The oriental populations are very close genetically to the two groups of olive clones cultivated in the eastern and in the western parts of the Basin, respectively, suggesting that most cultivars of the Mediterranean Basin originated from plants selected in the Middle East, as suggested previously from cpDNA, mtDNA and RAPDs analysis (Besnard and Bervillé 2000; Besnard et al, 2001a, 2002). However, in the western group, a few cultivars (particularly from Sicily, Corsica and Andalusia) showed allozyme characteristics similar to those found in the western oleaster populations supporting the previous evidence of a multilocal selection of cultivars in olive (eg Besnard and Bervillé, 2000; Besnard et al, 2001c; Bronzini de Caraffa et al, 2002a, b; Contento et al, 2002). In the present study, close genetic relationships were observed between the unselected oleaster populations of both the intermediate and western parts of the Basin, suggesting that most of these populations may derive, at least partly, from cultivated olive clones, many of them being close genetically and, as reported above, probably derived from selection in the same eastern area.

\section{Genotype structure in oleasters and in cultivated olive} In addition to distinct allele distributions and frequencies, substantial genotype differences were observed between oleasters (whatever their origin) and cultivated olives with, at most enzyme loci, significantly higher heterozygosity in the former group than in the latter. Moreover, heterozygosity was particularly low in olive cultivated in the eastern Mediterranean Basin, as compared to the cultivated olives of the occidental part. This difference was due mainly to the occurrence of higher heterozygosity in the several areas where substantial olive material was selected and cultivated locally, for example, in southern Morocco (Ouazzani et al, 1996). The trees originated very probably from hybridisation either between distinct cultivars or between cultivars and geographically close oleasters. In several recent studies using dominant nuclear markers (eg RAPDs, AFLPs and ISSRs), a substantial, but not complete, discrimination was observed between cultivars from various geographical origins and oleasters from populations distributed over the Mediterranean Basin, each represented by a single individual tree, although no genetic marker was identified by the authors to discriminate unambiguously between wild oleasters and the putative feral forms (Angiolillo et al, 1999; Besnard et al, 2001a; Vargas and Kadereit, 2001; Bronzini de Caraffa et al, 2002a, b). Such results were observed even when the oleasters were collected in disturbed areas close to olive groves and were considered as being of feral origin (Angiolillo et al, 
1999), and also in feral oleasters growing in Australia, where genuinely wild olive (in O. europaea) is not expected to grow (Mekuria et al, 2002). From the results of the present work, we suggest that the nuclear genetic differentiation observed between oleasters (whatever their origin) and cultivated olive may be attributable mostly to heterozygosity level differences and, very occasionally, to distinct allelic composition between these two fully interfertile partners of the same species. In addition, the occurrence of lower heterozygosity in cultivated olive than in oleasters suggests that intensive selection involving inbreeding may have taken place under cultivation originally to obtain particular characteristics in the olive cultivars (very probably, larger sized fruits and/or higher oil content).

The substantial allele and genotype variation observed in the oleaster populations analysed in the present work suggests that a portion of that plant material may constitute genetic resources for further breeding of olive material adapted to the various climate conditions occurring in the species' distribution area. Moreover, our discovery of genuinely wild olive in a few areas of the Mediterranean Basin makes it necessary to develop conservation strategies to maintain environmental conditions for the survival of large populations of oleasters properly isolated from cultivated olive.

\section{Acknowledgements}

We thank S Dettori, A Istanbouli, S Leonardi, A Quilichini, L Toumi, I Trujillo-Navas, P Villemur and D Zohary for their assistance with collection of olive material. We are grateful to D Claret, S Debray and V Sarda for technical assistance and, more particularly, to J Aronson for making useful suggestions on how to improve the paper.

\section{References}

Alcantara JM, Rey PJ, Valera F, Sanchez-Lafuente M (2000). Factors shaping the seedfall pattern of a bird-dispersal plant. Ecology 81: 1937-1950.

Amane M, Lumaret R, Hany V, Ouazzani N, Debain C, Vivier G et al (1999). Chloroplast-DNA variation in cultivated wild olive (Olea europaea L. Theor Appl Genet 99: 133-139.

Angiolillo A, Mencuccini M, Baldoni L (1999). Olive (Olea europaea L.) genetic diversity assessed by amplified fragment length polymorphisms. Theor Appl Genet 98: 411-421.

Anon (1989). Biomeco (Version.3.7): Groupe de biométrie. Centre d'Ecologie Fonctionnelle et Evolutive. CNRS: Montpellier, France.

Belkhir K, Borsa P, Chikhi L, Raufaste N, Bonhomme F (2001). GENETIX. Logiciel sous Windows TM pour la génétique des populations. Release 4.1. Laboratoire Génome et Populations, CNRS UPR 9060, University of Montpellier II: France.

Besnard G, Baradat P, Bervillé A (2001c). Genetic relationships in the olive (Olea europaea L.) reflect multilocal selection of cultivars. Theor Appl Genet 102: 251-258.

Besnard G, Baradat PH, Breton C, Khadari B, Bervillé A et al (2001a). Olive domestication from structure of oleasters cultivars using nuclear RAPDs mitochondrial RFLPs. Genet Sel Evol sp: 1-19.

Besnard G, Baradat P, Chevalier D, Tagmount A, Bervillé A et al (2001b). Genetic differentiation in the olive complex (Olea europaea L.) revealed by RAPDs and RFLPs in the rRNA genes. Genet Res Crop Evol 48: 165-182.
Besnard G, Bervillé A (2000). Multiple origins for Mediterranean olive (Olea europaea L. ssp. europaea) based upon mitochondrial DNA polymorphisms. CR Acad Sci Paris Life Sci 323: 173-181.

Besnard G, Khadari B, Baradat P, Bervillé A (2002). Olea europaea (Oleaceae) phylogeography based on chloroplast DNA polymorphism. Theor Appl Genet 104: 1353-1361.

Bronzini de Caraffa V, Giannettini J, Gambotti C, Maury J (2002b). Genetic relationships between cultivated wild olives of Corsica Sardinia using RAPD markers. Euphytica 123: 263-271.

Bronzini de Caraffa V, Maury J, Gambotti C, Breton C, Bervillé A, Giannettini J et al (2002a). Mitochondrial DNA variation RAPD mark oleasters olive feral olive from Western and Eastern Mediterranean. Theor Appl Genet 104: 1209-1216.

Chevalier A (1948). L'origine de l'olivier cultivé et ses variations. Rev Int Bot Appl Agric Trop 28: 1-25.

Claros MG, Crespillo ML, Aguilar ML, Canovas FM (2000). DNA fingerprinting classification of geographically related genotypes of olive-tree (Olea europaea L.). Euphytica 116: 131-142.

Contento A, Ceccarelli M, Gelati MT, Maggini F, Baldoni L, Cionini G et al (2002). Diversity of olea genotypes the origin of cultivated olives. Theor Appl Genet 104: 1229-1238.

Daget $P$ (1977). Le bioclimat méditerranéen: caractères généraux modes de caractérisation. Vegetatio 34: 1.

Escoufier Y (1975). Le positionnement multidimentionnel. Rev Stat Appl 4: 5-14.

Griggs WH, Hartmann HT, Bradley MV, Iwakiri BT, Whisler JE (1975). Olive pollination in California. Calif Agric Exp Stat Bull 869: 3-50.

Hess J, Kadereit JW, Vargas P (2000). The colonization history of Olea europaea Lin Macaronesia based on internal transcribed spacer 1 (ITS-1) sequences, randomly amplified polymorphis DNAs (RAPD), and intersimple sequence repeats (ISSR). Mol Ecol 9: 857-868.

Li CC, Horvitz DG (1953). Some methods of estimating the inbreeding coefficient. Am J Human Genet 5: 107-117.

Liphschitz N, Gophna R, Hartman M, Biger G (1991). The beginning of Olive (Olea europaea L.). Cultivation in the old world: a reassessment. J Archaeol Sci 18: 441-453.

Lumaret R, Amane M, Ouazzani N, Baldoni L (2000). Chloroplast DNA variation in the cultivated wild olive taxa of the genus Olea L. Theor Appl Genet 101: 547-553.

Lumaret R, Ouazzani N (2001). Ancient wild olives in Mediterranean forests. Nature 413: 700.

Lumaret R, Ouazzani N, Michaud H, Villemur P (1997). Cultivated olive and oleaster: two closely connected partners of the same species (Olea europaea L.): evidence from allozyme polymorphism. Bocconea 7: 39-42.

Médail F, Quérel P, Besnard G, Khadari B (2001). Systematics ecology phylogeographic significance of Olea europaea L. ssp. maroccana (Greuter \& Burdet) P. Vargas et al, a relictual olive tree in south-west Morocco. Bot J Linn Soc (London) 137: 249-266.

Mekuria GT, Collins G, Sedgley M (2002). Genetic diversity within an isolated olive (Olea europaea L.) population in relation to feral spread. Sci Hortic 94: 91-105.

Nei M (1978). Estimation of average heterozygosity and genetic distance from a small number of individuals. Genetics 89: 583-590.

Ouazzani N, Lumaret R, Villemur P (1994). An evaluation of approach the genetic variability of olive tree using enzymatic markers. Acta Hortic 356: 91-94.

Ouazzani N, Lumaret R, Villemur P, Di Giusto F (1993). Leaf allozyme variation in cultivated and wild olive trees (Olea europaea L.). J Heredity 84: 34-42.

Ouzzani N, Lumaret R, Villemur P (1995). Apport du polymorphisme alloenzymatique à l'identification variétale de l'Olivier (Olea europaea L.). Agronomie 15: 1-7. 
Ouzzani N, Lumaret R, Villemur P (1996). Genetic variation in the olive tree (Olea europaea L.) cultivated in Morocco. Euphytica 91: 9-20.

Raymond M, Rousset F (1995). GENEPOP (v.1.2), population genetics software for exact tests and ecumenicism. J Heredity 86: $248-249$.

Rivas-Martinez S (1981). Les étages bioclimatiques de la végétation de la péninsule ibérique. Ann Jard Bot Madrid 37: 251-268.

Spennemann DHR, Allen LR (2000). Feral olives (Olea europaea) as future woody weeds in Australia. Ann Rev Aust J 40: 889-901.

Terral JF, Arnold-Simard G (1996). Beginnings of olive cultivation in eastern Spain in relation to Holocene bioclimatic changes. Quat Res 46: 176-185.
Trujillo I, Rallo L, Arus P (1995). Identifying olive cultivars by isozyme analysis. I Am Soc Hortic Sci 120: 318-324.

Vargas P, Kadereit JW (2001). Molecular fingerprinting evidence (ISSR, inter-simple sequence repeats) for a wild status of Olea europaea L. (Oleaceae) in the Eurosiberian North of the Iberian Peninsula. Flora 196: 142-152.

Wright S (1965). The interpretation of population structure by Fstatistics with special regard to systems of mating. Evolution 19: 395-420.

Zohary D (1994). The wild genetic resources of the cultivated olive. Acta Hortic 356: 62-65.

Zohary D, Hopf M (1993). Domestication of Plants in the Old World. Oxford University Press: Oxford.

Zohary D, Spiegel-Roy P (1975). Beginnings of fruit growing in the old world. Science 187: 319-327. 